\title{
Research On The Statistical Model Of The Cost Savings In Logistics Transportation
}

\author{
Gu Quan mei
}

Qingdao Huanghai University , 266427

\begin{abstract}
Keywords: statistical model; physical transportation; transportation cost; freight volume;
\end{abstract}
\begin{abstract}
In the research process of statistical modeling method on the conservation of transport logistics costs, the current statistical model in the establishment of logistics transport save cost, has defects of inappropriate statistics of the cost of logistics and transport and establish a model error. Therefore, a statistical modeling method based on the agent algorithm for saving cost in logistics transportation is proposed. The method is on basis of transport and logistics cost, split logistics and transport of each process into the cost calculation to account the logistics cost in the enterprise and integrate in the minimum cost rule. Under the premise of ensuring the time and quality of logistics transportation, the distribution of freight volume is performed with the minimum cost of transportation. On the basis of the application of statistical data on the cost saving of logistics transportation, the least squares fitting of the cost in logistics transportation is carried out. A statistical forecasting model of cost saving in logistics transportation is constructed using the method of coordinate rotation of the accelerating step size to solve the exact completion of the logistics transportation cost savings. The experimental results show that the method of saving the cost of the logistics transportation based on the agent algorithm is highly accurate and practical.
\end{abstract}

\section{Introduction}

Logistics, as one of the basic activities of modern economic operation, has a huge logistical support for the production and operation of enterprises ${ }^{[1]}$. But the high cost of logistics industry in the development of logistics enterprises in our country is far behind the developed countries in Europe $^{[2]}$ and the United States ${ }^{[3]}$, maximize reduction of logistics cost become significant issues in competition with Europe and the United states. In this condition, the establishment of accurate statistical model of cost saving in logistics transportation is an effective way to solve this problem, which has caused many experts and scholars' attention ${ }^{[4]}$. Due to logistics and transport in saving cost of statistical modeling method is of far-reaching significance to the development, so it has become the focus study of the personage and has received extensive attention, at the same time, there are a lot of good method presented ${ }^{[5]}$.

At present, the main statistical modeling method is based on the ant colony algorithm ${ }^{[6]}$, genetic algorithm $^{[7]}$ and particle algorithm ${ }^{[8]}$. Among them, the commonly used method is based on ant colony algorithm ${ }^{[9]}$. But using the above method in the establishment of the logistics transportation cost saving statistical model, the cost of logistics transportation in the improper, there is a big problem of the model error ${ }^{[10]}$. In view of the above problems, a statistical modeling method based on the agent algorithm for saving cost in logistics transportation is proposed. This method has high accuracy and practicability.

\section{2 statistical modeling of the cost savings in logistics transportation}

In saving cost of statistical modeling of logistics and transport, the first hypothesis of enterprise logistics transportation cost function is a linear function, i.e., the average cost of logistics and transport is a fixed constant, and cargo transport flow does not matter. Specific steps are detailed as follows.

In statistical modeling process of saving cost in logistics and transport, the sampling period of each logistics transportation cost savings is calculated in logistics transportation cost statistical 
probability model $\mu_{j}(k)$ conservation, type of $\mu_{j}(k)$ are calculated using:

$\mu_{j}(k)=p\left(m_{j}(k) / Z^{K}\right)=\frac{1}{C} p\left(z(k) / m_{j}(k), Z^{K-1}\right) \cdot P p\left(m_{j}(k) / Z^{K-i}\right)$

Through the calculation of $\mu_{j}(k)$ with the statistical model of logistics transportation cost, the statistical model of the saving cost in the logistics transportation is:

${ }_{a}^{2}=\mid \begin{aligned} & \frac{4-\pi}{\pi}\left[a_{\max } \mu_{j}(k)-\ddot{x}(k / k)\right]^{2} \\ & \frac{4-\pi}{\pi}\left[a_{-\max } \mu_{j}(k)-\ddot{x}(k / k)\right]^{2}\end{aligned}$

\section{3 principles of statistical modeling and optimization method for cost saving in logistics transportation}

\section{1 optimization of cost in logistics transportation}

In optimization modeling process of logistics transportation, it is first to transport and logistics cost as a foundation, second to split each process into the cost calculation method in logistics and transport accounting the logistics cost in the enterprise, last to integrate in the minimum cost rule. In the premise of ensuring the logistics transportation time and quality, the distribution of freight volume is carried out with the minimum cost of transportation. Specific steps are as follows.

Provided logistics enterprise logistics has $a$ transport cost objects, $b$ transport links, depletion of $t$ resources, matrix $M$ as logistics and transport business cost, cost matrix $N$ as loss direct artificial, matrix $H$ as wasting resource of the direct cost object, loss amount of $T$ as cost job, operation loss per unit amount of resources design as $s$, unit price of resources as $p, S_{j e}$ as cost drivers of $j$ transportation operation loss of $e$ transport resources, the motivation model of logistics and transport costs is obtained:

$M=T \cdot S \cdot P+N+H$

In the process of statistical optimization of the cost saving in the logistics transportation, the above formula is extended as:

$\left[\begin{array}{c}m_{1} \\ m_{2} \\ \vdots \\ m_{a}\end{array}\right]=\left[\begin{array}{ccc}t_{11} & t_{12} & t_{1 n} \\ t_{21} & t_{22} & t_{2 n} \\ t_{a 1} & t_{a 2} & t_{a m}\end{array}\right] \times\left[\begin{array}{ccc}s_{11} & s_{12} & s_{1 t} \\ s_{21} & s_{22} & s_{2 t} \\ s_{b 1} & s_{b 2} & s_{b t}\end{array}\right] \times\left[\begin{array}{c}p_{1} \\ p_{2} \\ p_{3} \\ p_{4}\end{array}\right]+\left[\begin{array}{c}N_{1} \\ N_{2} \\ N_{3} \\ N_{4}\end{array}\right]+\left[\begin{array}{c}H_{1} \\ H_{2} \\ H_{3} \\ H_{4}\end{array}\right]$

On basis of the above formulas of issues inducing logistics and transport costs, logistics and transport of each process split into direct costs, depletion expense of second distribution and common costs so as to account enterprise cost.

Consider $f_{i j}$ as cost loss of $i$ transport object, $j$ as issues of transportation resource cost, gij as set $\mathrm{i}$ transport costs of $\mathrm{j}$ transport operations, $v$ as located number of $j$ operations, it is drawn as

$$
Z_{j}=\sum_{i=1}^{b} g_{i j} o_{j}
$$

Once the total cost of the logistics and transport is calculated, according to which driver rate is received, freight distribution of the target is in principle of minimizing transportation costs with the formula as:

$M N_{1}=\sum f_{i j} * Z_{j}$

which satisfies $j=1,2 \ldots, a$ condition。

In the upper condition, the conditions require to meet $j=1,2 \ldots, a$. 


\section{2 statistical modeling of cost savings in logistics transportation}

In the statistical optimization modeling process of logistics transportation, the least squares fitting of the cost of logistics transportation is carried out by using the following formula:

$Y_{2}=A+B_{t}^{-p}$

$Y_{1}=A+B_{e}^{c t}$

In process of the statistical forecasting model, the model of logistics transportation is established:

$$
\begin{aligned}
& M I N Q_{1}=\sum_{i=1}^{n}\left(Y_{i}-A-B e^{-c t i}\right)^{2} \\
& M I N Q_{2}=\sum_{i=1}^{n}\left(Y_{i}-A-B t_{i}^{-p}\right)^{2}
\end{aligned}
$$

To optimize statistical modeling of the cost saving in the logistics transportation, the problem of saving cost is converted to an unconstrained optimization equation:

$$
R=\sqrt{1.0-\frac{Q}{\sum_{i=1}^{n} Y_{i}^{2}-\left[\sum_{i=1}^{n} Y_{i}\right]^{2} / n}}
$$

In the above formula, A represents the basic cost of logistics transportation.

In process of optimization modeling, the acceleration step method of coordinate rotation is employed to solve the unconstrained optimization problem, with the lowest cost to achieve logistics transportation cost saving. It is expressed as:

$$
F\left(t_{1}, t_{2}, \ldots, t_{n}\right)=\sum_{i=1}^{n}\left(A_{i}+B_{i} e^{-c i t i}\right)+\lambda\left[\sum_{i=1}^{n}\left|\partial_{i}\right| t_{j}-t o\right]
$$

\section{4 experiments and simulation}

In order to show that the proposed driver algorithm in logistics transportation based on saving cost statistical modeling method is effective, an experiment is carried out. The experimental data were collected from four transmitted of logistics enterprises in Guangzhou station, the logistics system has 3 level.

Using the improved algorithm and the traditional algorithm to carry out the statistical modeling experiment of the cost saving in the logistics transportation, the two algorithms are compared with the results of the model, which is used to measure the effectiveness of different algorithms. Modeling results of different algorithms are shown in Table 2 and table 1.

\begin{tabular}{llllll}
\multicolumn{5}{l}{ Table 1 the traditional algorithm for saving cost forecast data in logistics } \\
\hline $\begin{array}{l}\text { Transfer } \\
\text { station }\end{array}$ & $\begin{array}{l}\text { The size of } \\
\text { the distance } \\
\text { /KM }\end{array}$ & $\begin{array}{l}\text { Actual } \\
\text { logistics } \\
\text { transportation } \\
\text { value /KG }\end{array}$ & $\begin{array}{l}\text { Predicted } \\
\text { transportation } \\
\text { value /KG }\end{array}$ & $\begin{array}{l}\text { Error value } \\
\text { /KG }\end{array}$ & $\begin{array}{l}\text { Relative } \\
\text { error value }\end{array}$ \\
\hline station 1 & 2.46 & 0.671 & 0.677 & -0.06 & -0.09 \\
station 2 & 2.58 & 0.589 & 0.571 & -0.12 & -0.05 \\
station 3 & 2.93 & 0.678 & 0.578 & -0.07 & -0.10 \\
station 4 & 2.17 & 0.614 & 0.514 & -0.04 & -0.07 \\
\hline
\end{tabular}


Table 2 improved algorithm for saving cost forecast data in logistics transportation

\begin{tabular}{llllll}
\hline $\begin{array}{l}\text { Transfer } \\
\text { station }\end{array}$ & $\begin{array}{l}\text { The size of } \\
\text { the distance } \\
\text { /KM }\end{array}$ & $\begin{array}{l}\text { Actual } \\
\text { logistics } \\
\text { transportation } \\
\text { value /KG }\end{array}$ & $\begin{array}{l}\text { Predicted } \\
\text { transportation } \\
\text { value /KG }\end{array}$ & $\begin{array}{l}\text { Error value } \\
\text { /KG }\end{array}$ & $\begin{array}{l}\text { Relative } \\
\text { error value }\end{array}$ \\
\hline Station 1 & 2.46 & 0.671 & 0.670 & -0.003 & -0.001 \\
Station 2 & 2.58 & 0.589 & 0.580 & -0.005 & -0.002 \\
Station 3 & 2.93 & 0.678 & 0.676 & -0.004 & -0.001 \\
Station 4 & 2.17 & 0.614 & 0.612 & -0.002 & -0.001 \\
\hline
\end{tabular}

In table 1 and table 2, it is seen that relative error of the improved algorithm is lower than the traditional algorithm. The reason is that the improved algorithm is optimized to minimize transportation cost in the goal freight distribution so as to perform accurate completion of cost saving in logistics and transport statistics.

In summary, it can be explained that the statistical modeling method based on the driver's algorithm in logistics transportation cost saving, and the modeling method has high accuracy and practicability.

\section{5 conclusions}

To solve the defects that the cost of the logistics transportation is improper and the model error of the model error is larger, a statistical modeling method of saving cost in logistics transportation based on agent algorithm is proposed. The method is employed firstly to search issues occurred in transport and logistics cost as a foundation, secondly to split logistics and transport of each process with the cost calculation method in accounting the logistics cost of enterprise, then to integrate in the minimum cost rule. Under the premise of transport time and the quality, freight distribution of the target is located with minimum cost. The least squares fitting of transport cost is proposed with statistical saving data to build statistical prediction model, with coordinate alternation method to exactly solve statistics of cost savings. The experimental simulation shows that the method of saving the cost of the logistics transportation based on the agent algorithm has high accuracy and practicability.

The topic is: the discussion of the educational alliance of cultivating modern professional portuale logistic talents — - take Qingdao Vocational Education as an example Shangdong province education scientific planning office issue number: $2013 \mathrm{GG084}$

\section{Reference}

[1] Liao Ling.Based on supply and demand imbalance transportation model to reduce the logistics cost of [J]. technology and enterprises, 2013, (9): 54-54.

[2]Wan Jinghua.Cost accounting and optimization control of the international crude oil logistics transportation cost accounting and optimization [J]. logistics technology, 2013, 32 (12): 290-292.

[3]Fang Chenyang. Effective measures to reduce the cost of Chenyang express transportation logistics in [J]. Chinese trade, 2014, (28): 127-127.

[4] Hessler, Xu Fuyuan. Uncertain demand logistics transport enterprises cooperative game model [J]. Transportation systems engineering and information, 2013, 13 (5): 22-29.

[5] Ma Li, Li Kun, Wang Yinzhu. Distribution network resources allocation of [J]. statistics and information forum, 2013, 28 (7): 27-31.

[6] Li Wenchao, Lixin, he Dan. Based on the system dynamics model of logistics node city tanker linkage [J]. Statistics and decision, 2014, (21): 39-42.

[7] Xie Yan. Research on the production logistics tracking for iron and steel enterprises based on cost control [J]. logistics technology: equipment version, 2014, (4): 36-41. 
[8] Zhao Xue. Research on regional logistics development based on DEA model [J]. railway transportation and economy, 2013, 35 (8): 67-70.

[9] Shangguan Xuming. Based on unrestricted vector autoregression (VaR) model of regional logistics and foreign trade to the statistical data from 1990 to 2010 in Jiangsu Province as empirical analysis [J]. Journal of [J]. Xinyang Normal University: Philosophy and Social Sciences Edition, 2013, (5): 88-94. Research on the relationship between the growth of

[10] Gao Xiaowei. Research on the logistics transportation route problem based on improved QPSO algorithm [J]. Computer simulation, 2013, 30 (8): 169-172. 